\title{
DAILY KILOMETRAGE ANALYSIS FOR SELECTED VEHICLE GROUPS
}

\author{
Dariusz Dobrowolski', Paweł Droździel², Radovan Madleňák ${ }^{3}$, Dariusz Siłuch ${ }^{4}$, Iwona Rybicka² \\ 1 Maria Curie Skłodowska University, Faculty of Mathematics, Physics and Computer Science, Akademicka 9, \\ 20-033, Lublin, Poland, e-mail: dariusz.dobrowolski@poczta.umcs.lublin.pl \\ 2 Lublin University of Technology, Faculty of Mechanical Engineering, Nadbystrzycka 36, 20-618 Lublin, Poland, \\ e-mail: p.drozdziel@pollub.pl; i.rybicka@pollub.pl \\ 3 University of Žilina, Faculty of Operation and Economics of Transport and Communications, Univerzitna 1, \\ 010 26, Žilina, Slovakia, e-mail: radovan.madlenak@fpedas.uniza.sk \\ ${ }^{4}$ University of Life Sciences in Lublin, Faculty of Production Engineering, Głęboka 28, 20-612, Lublin, Poland, \\ e-mail: dariusz.siluch@up.lublin.pl
}

Received: 2018.05.03

Accepted: 2018.06.09 Published: 2018.09.01

\begin{abstract}
The article presents a statistical analysis of daily kilometrages of vehicles operated by a selected transport company in the period of three consecutive years (2013-2015). Company vehicles have been divided into four categories depending on gross vehicle mass and the type of their intended transport use. Statistical analyses of daily vehicle kilometrages showed statistically significant differences in daily kilometrage across different vehicle categories and in various months throughout the year.
\end{abstract}

Keywords: vehicles, kilometrages, transport, statistics.

\section{INTRODUCTION}

The analysis of large data sets using modern statistical analysis tools helps retrieve useful data with a potential for practical applications. Such analyses are successfully used for data related to vehicle use. The more diverse the data regarding vehicle use, the more reliable results can be obtained to be used as the basis for drawing conclusions and developing recommendations for commercial vehicle users.

In their recent endeavours, scholars have focused on various aspects of vehicle use [9, 1]. Article [13] addresses the framework for Monitoring Vehicle Outliers based on Clustering (MVOC). This framework helps analyse cluster data to anticipate any outliers. The authors also present the statistical significance of the results through significance tests.

Article [6] focuses on identifying correlations between the cumulated vehicle kilometrage and fuel consumption by their internal-combus- tion engines. Such analyses are possible thanks to the development of a unique longitudinal database of more than 600,000 odometer and fuel purchase diaries.

Nowadays, the storage of large data resources is not a problem, so it is completely reasonable to collect all the information concerning vehicle use and to store them in databases. This facilitates ever more accurate statistical analyses [12], which produce more and more knowledge. Such knowledge can significantly improve the economics of transport companies $[7,10]$ by delivering information, e.g., on the costs of repairs [4, $5,8]$ and vehicle wear [11], and also helping anticipate potential breakdowns or incidents that put the vehicle out of operation.

The article presents a statistical analysis for an essential aspect of vehicle use, namely daily kilometrage, in one of Lublin's transport companies over a period of three consecutive years (2013-2015). This analysis can serve as a basis for further studies on data concerning vehicle use. 
Future studies will also take fuel consumption, replaced parts, and consumables into consideration.

\section{STUDIED VEHICLES}

In the above-mentioned time frame, there were 287 vehicles in operation in the analysed transport company. These vehicles were grouped by the company into 4 categories, based on their gross vehicle mass (GVM).

Category I includes vehicles whose GVM is up to 3.5 tonnes. These vehicles are generally used in Lublin and its immediate vicinity. Alternatively, they might be used for quick transport journeys across the country. Category I includes 203 cars, with the most numerous groups being Peugeot Boxer (52), Citroen Berlingo (35), Citroen Jumper (32), Peugeot Partner (21), and Ford Transit (13).

Category II comprises vehicles with GVM above 3.5 but up to 12 tonnes. These vehicles are used mainly for transporting goods between smaller branches of the company. Category II includes 13 vehicles, such as Iveco Eurocargo (9), MAN TGL (3) and Star M70 (1).

Category III comprises vehicles with GVM between 12 and 18 tonnes. These vehicles serve similar purposes as those in Category II, but are usually used for transporting bulk packaging between major branches of the company. Category III includes 13 vehicles, such as Iveco Eurocargo (7), MAN LC (5) and Mercedes Axor (1).

Category IV comprises vehicles with GVM above 18 tonnes. These vehicles are generally used for two purposes. The first are regular trips between major company hubs across the country, and the second are pallet shipment services commissioned by third parties. Category IV includes 56 vehicles, such as Iveco Stralis (49), MAN TGS (3), Volvo FM (2), Mercedes Actros (1), and Mercedes Axor (1).

\section{STATISTICAL ANALYSIS OF THE RESULTS}

The statistical analysis of daily kilometrages started with the identification of baseline statistics for each vehicle category. Statistical parameters $[2,3]$ were established for each category separately. The statistical analysis was performed with the use of STATISTICA 13 software. Baseline statistics for each vehicle category are presented in Table 1.

In order to check whether there are significant differences between vehicle categories in terms of their daily kilometrages, an analysis of variance was conducted.

One of the fundamental assumptions of the analysis of variance (ANOVA) for one-way classification, which examines the effect of only one qualifying factor on study results, is that the investigated independent populations have normal distribution. In order to verify whether this condition is met, analysed daily kilometrages for each vehicle category were F-tested against the normality of their $\chi^{2}$ distributions. The significance level for statistical data analysis was established at $\alpha=0.05$. For $\chi^{2}$ F-test results, please consult Table 2.

The $\chi^{2}$ F-test showed that daily kilometrages do not have normal distributions in any vehicle category. In view of this, classical analysis of variance could not be conducted for the recorded daily kilometrages.

Table 1. Position and dispersion of daily kilometrages

\begin{tabular}{|c|c|c|c|c|c|c|c|}
\hline Category & $\begin{array}{c}\text { Average } \\
\text { value }\end{array}$ & Median & $\begin{array}{c}\text { Minimum } \\
\text { value }\end{array}$ & $\begin{array}{c}\text { Maximal } \\
\text { value }\end{array}$ & Variance & Standard deviation & $\begin{array}{c}\text { Standard } \\
\text { error }\end{array}$ \\
\hline I & 127 & 101 & 1 & 1144 & 7738 & 88 & 0,30 \\
\hline II & 116 & 108 & 1 & 1212 & 6009 & 78 & 1,11 \\
\hline III & 138 & 115 & 1 & 1152 & 13449 & 116 & 1,43 \\
\hline IV & 308 & 214 & 1 & 1451 & 89216 & 299 & 1,66 \\
\hline
\end{tabular}

Table 2. Results of $\chi^{2}$ F-test with normal distribution

\begin{tabular}{|c|c|c|c|}
\hline Category & $\mathbf{x}^{2}$ & $\mathbf{p}-$ value & Normal \\
\hline I & 8681 & 0,00000 & No \\
\hline II & 680 & 0,00000 & No \\
\hline III & 1010 & 0,00000 & No \\
\hline
\end{tabular}




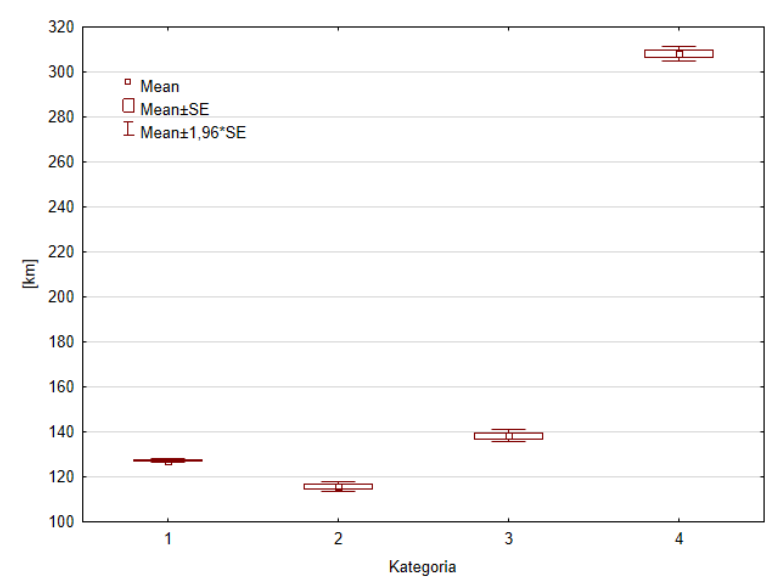

Fig. 1. Categorised box plot for vehicle category as an independent variable, and daily kilometrage as a dependent variable

Therefore, in order to check whether there were significant daily kilometrage differences between vehicle categories, the study used the Kruskal-Wallis test, which does not rely on the assumption of normality. The results of the K-W test are presented in Table 3.

The Kruskal-Wallis test score $\mathrm{H}=7012.831$ and the test probability value $p=0.000$ lead to the rejection of the null hypothesis about the lack of significant differences between the studied groups, suggesting that daily kilometrages show significant statistical differences across vehicle categories.

A multiple comparisons (post-hoc) test was carried out to identify the categories of vehicles which show significant differences in daily kilometrages. The results of this test are presented in Table 4.

The test showed that no statistically significant differences were found only between the daily kilometrages in vehicle Categories I and III, while the differences between the remaining categories were statistically significant.

Figure 1 shows a box-and-whisker diagram (box plot) which is a graphic representation of daily kilometrages for each vehicle category.

In order to verify whether the differences in daily kilometrages across vehicle categories are repeatable for each of the three analysed years, the Kruskal-Wellis test was repeated for each year separately. The results of the K-W test are presented in Table 5.

The results of the K-W test presented in Table 5 showed statistically significant differences in daily

Table 3. Results of the Kruskal-Wallis test for daily kilometrages

\begin{tabular}{|c|c|c|c|}
\hline \multicolumn{4}{|c|}{ Test Kruskala-Wallisa: H( 3, N= 132238) =7012,831 $\mathbf{p = 0 , 0 0 0}$} \\
\hline Category & Valid N & Rank sum & Average rank \\
\hline I & 88482 & 5422543894 & 61284,15 \\
\hline II & 4851 & 280694839 & 57863,29 \\
\hline III & 6575 & 404353682 & 61498,66 \\
\hline IV & 32330 & 2635918027 & 81531,64 \\
\hline
\end{tabular}

Table 4. Kruskal-Wallis multiple comparisons test results

\begin{tabular}{|c|c|c|c|c|}
\hline Category & I & II & III & IV \\
\hline I & - & 0,000000 & 1 & 0,000000 \\
\hline II & 0,000000 & - & 0,000003 & 0,000000 \\
\hline III & 1 & 0,000003 & - & 0,000000 \\
\hline IV & 0,000000 & 0 & 0 & - \\
\hline
\end{tabular}

Table 5. Results of the Kruskal-Wallis test for daily kilometrages of four categories of vehicles in the consecutive years of use

\begin{tabular}{|c|c|c|c|}
\hline Year & K-W Statistic's value & $\mathbf{p}$ - value & Are there differences decision \\
\hline 2013 & 2391,09 & 0,0000 & Yes \\
\hline 2014 & 2497,83 & 0,0000 & Yes \\
\hline 2015 & 2289,22 & 0,0000 & Yes \\
\hline
\end{tabular}



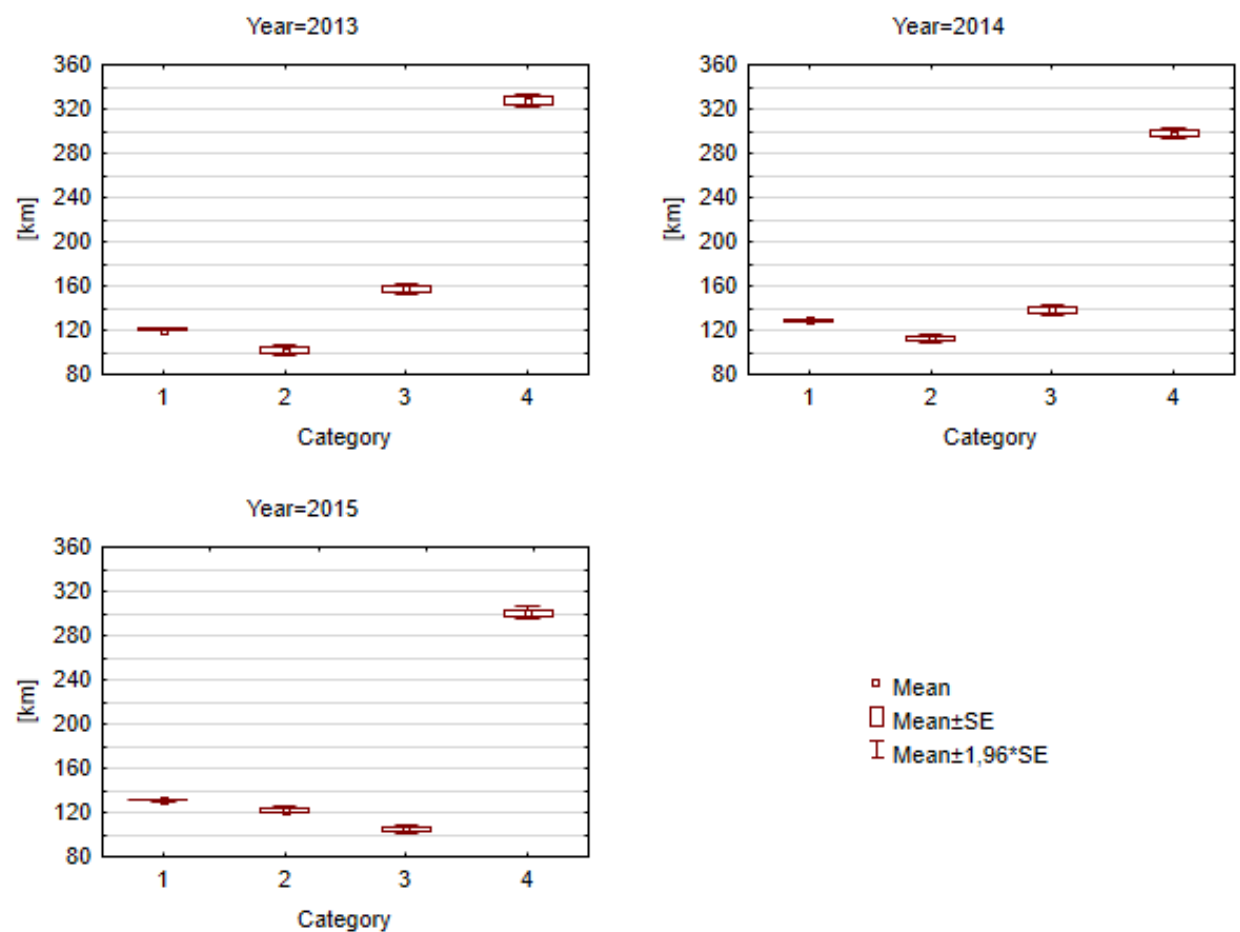

Fig. 2. Categorised box plot for vehicle category as an independent variable, and daily kilometrage as a dependent variable, in the three consecutive years

kilometrages in each of the three analysed years.

The subsequent multiple comparisons test showed that in 2013, statistically significant differences between daily kilometrages across vehicle categories were recorded for each category, in 2014 there were no statistically significant differences between Categories I and III, and in 2015 significant differences were not found between Categories I and II.

Figure 2 shows a box-and-whisker diagram (box plot) which is a graphic representation of daily kilometrages for each vehicle category over three consecutive years of use.

The next step in the analysis was to check whether daily kilometrages in each vehicle category differed in months throughout the year. In order to do this, the Kruskal-Wallis test was conducted again for the daily kilometrage, as a dependent variable, and months throughout the year, as a grouping variable. K-W tests were car- ried out for each year separately to see if the results were repeatable over the three consecutive years. The results of the K-W test for Category I vehicles are presented in Table 6 .

The results show no statistically significant differences in daily kilometrages of Category I vehicles between individual months throughout 2013, but in 2014 and 2015 such differences were observed. A multiple comparisons test was carried out to identify the months throughout the year which show significant differences in daily kilometrages. For 2014, the test showed that daily kilometrages in November and December were markedly different from daily kilometrages in the other months. Differences in daily kilometrages were also observed in January, April, July and October. In 2015, significant differences in daily kilometrages were observed in January and November. Differences between the other months were insignificant.

Table 6. Results of the Kruskal-Wallis test for daily kilometrages of Category I vehicles

\begin{tabular}{|c|c|c|c|}
\hline Year & K-W Statistic's value & $\mathbf{p}$ - value & Are there differences decision \\
\hline 2013 & 19,7544 & 0,0488 & No \\
\hline 2014 & 119,7331 & 0,0000 & Yes \\
\hline 2015 & 50,7084 & 0,0000 & Yes \\
\hline
\end{tabular}



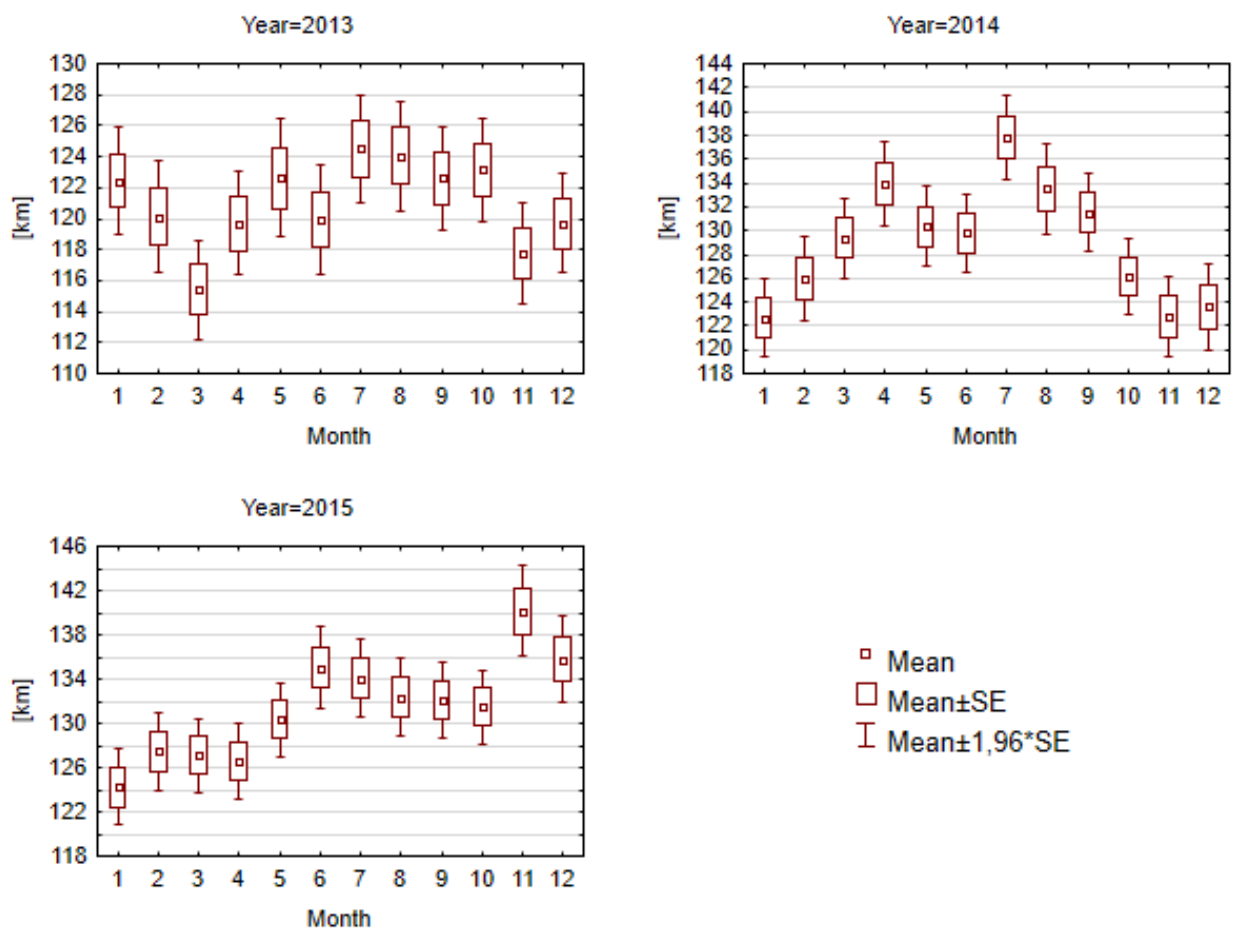

${ }^{\square}$ Mean

$\square$ Mean \pm SE

I Mean $\pm 1,96^{*} \mathrm{SE}$

Fig. 3. Categorized box plot for month as an independent variable, and daily kilometrage as a dependent variable - daily kilometrages of Category I vehicles
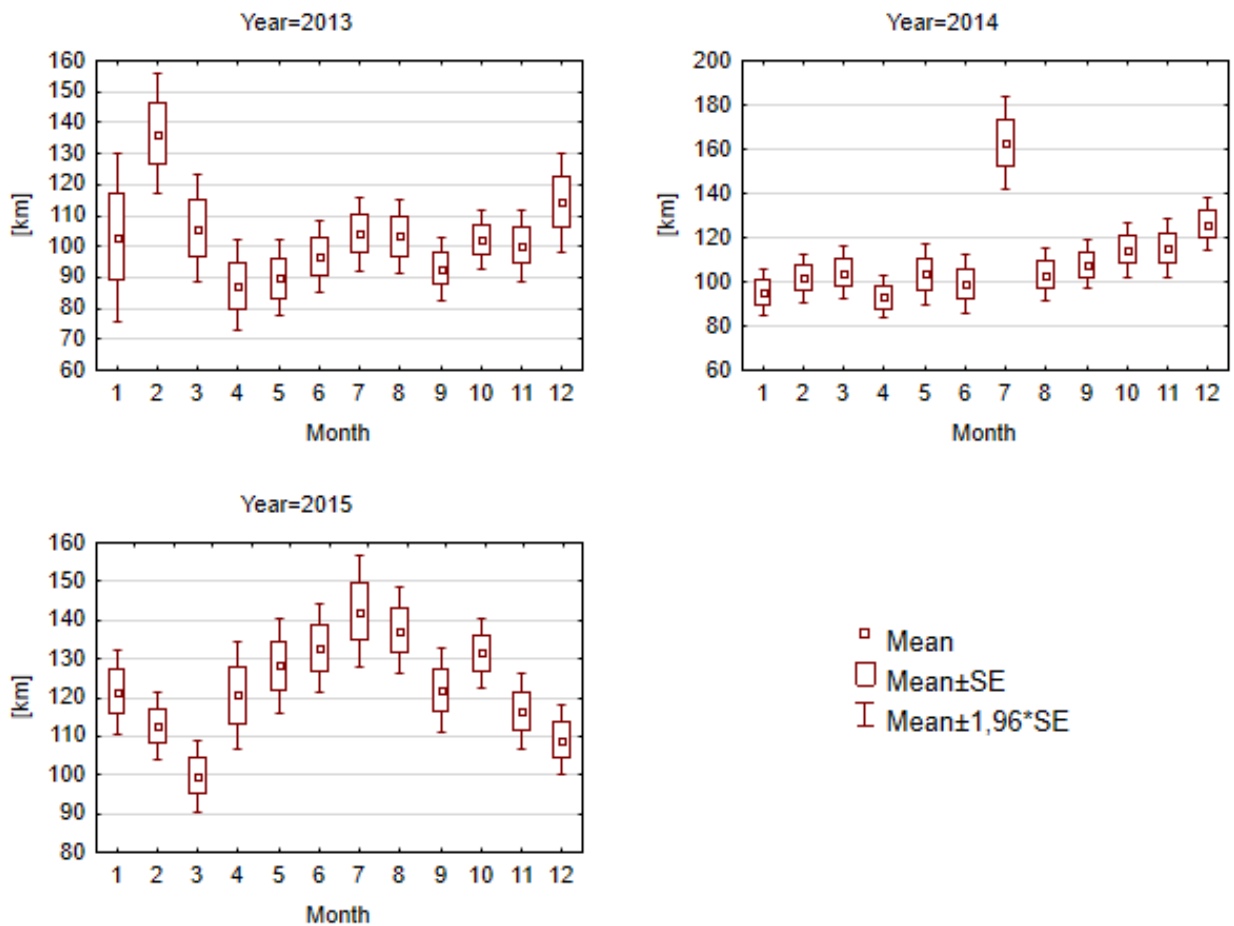

Fig. 4. Categorized box plot for month as an independent variable, and daily kilometrage as a dependent variable - daily kilometrages of Category II vehicles

Table 7. Results of the Kruskal-Wallis test for daily kilometrages of Category II vehicles

\begin{tabular}{|c|c|c|c|}
\hline Year & K-W Statistic's value & $\mathbf{p}$ - value & Are there differences decision \\
\hline 2013 & 32,6517 & 0,0006 & Yes \\
\hline 2014 & 50,4144 & 0,0000 & Yes \\
\hline 2015 & 48,4136 & 0,0000 & Yes \\
\hline
\end{tabular}



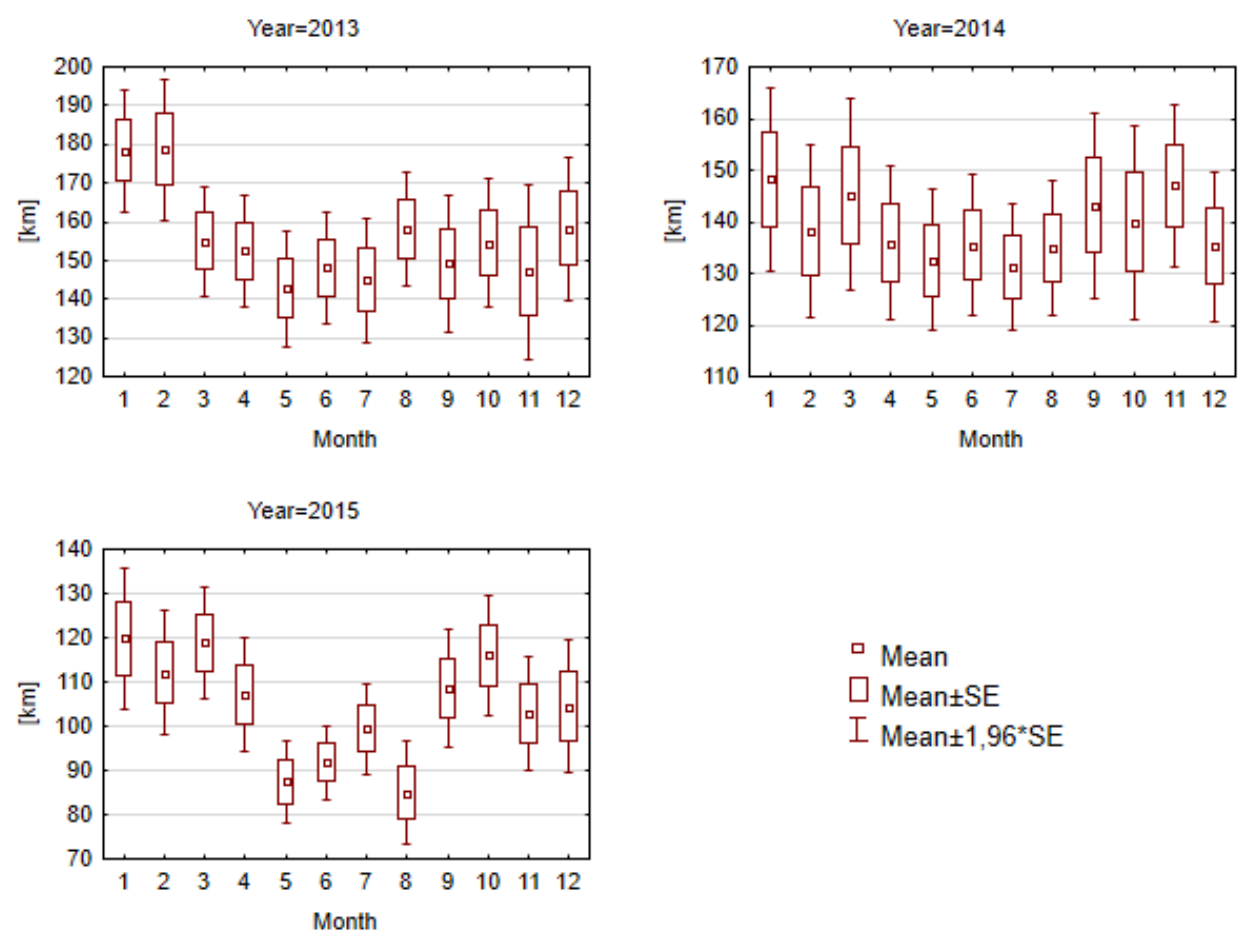

Fig. 5. Categorized box plot for month as an independent variable, and daily kilometrage as a dependent variable - daily kilometrages of Category III vehicles

Figure 3 shows a box-and-whisker diagram (box plot) which is a graphic representation of daily kilometrages for Category I vehicles in each month throughout the year.

A similar analysis was conducted for Category II vehicles. The results of the Kruskal-Wallis test for Category II vehicles are presented in Table 7. These results show statistically significant differences between daily kilometrages throughout the year across all three years.

The multiple comparisons test for Category II vehicles showed that in 2013 significant differences occurred only in February, in 2014 in July, and in 2015 in March and December. Figure 4 shows a box-and-whisker diagram (box plot) which is a graphic representation of daily kilometrages for Category II vehicles in each month throughout the year.

The results of the Kruskal-Wallis test for Category III vehicles are presented in Table 8 . The results show that no statistically significant differences in daily kilometrages between individual months were observed only in 2014 .

The multiple comparisons test for the other two years showed that differences between Category III vehicle kilometrages were negligible. Indeed, in 2013 such differences were found only between January and May, and in 2015 only between March and May.

Figure 5 shows a box-and-whisker diagram (box plot) which is a graphic representation of daily kilometrages for Category III vehicles in each month throughout the year.

The results of the Kruskal-Wallis test for Category IV vehicles are presented in Table 9. The results show that statistically significant differences in daily kilometrages between individual months were observed in all three consecutive years.

The analysis of the multiple comparisons test results for Category IV vehicles showed that in

Table 8. Results of the Kruskal-Wallis test for daily kilometrages of Category III vehicles

\begin{tabular}{|c|c|c|c|}
\hline Year & K-W Statistic's value & $\mathbf{p}$ - value & Are there differences decision \\
\hline 2013 & 22,8394 & 0,0186 & Yes \\
\hline 2014 & 6,2254 & 0,8579 & No \\
\hline 2015 & 25,9518 & 0,0066 & Yes \\
\hline
\end{tabular}



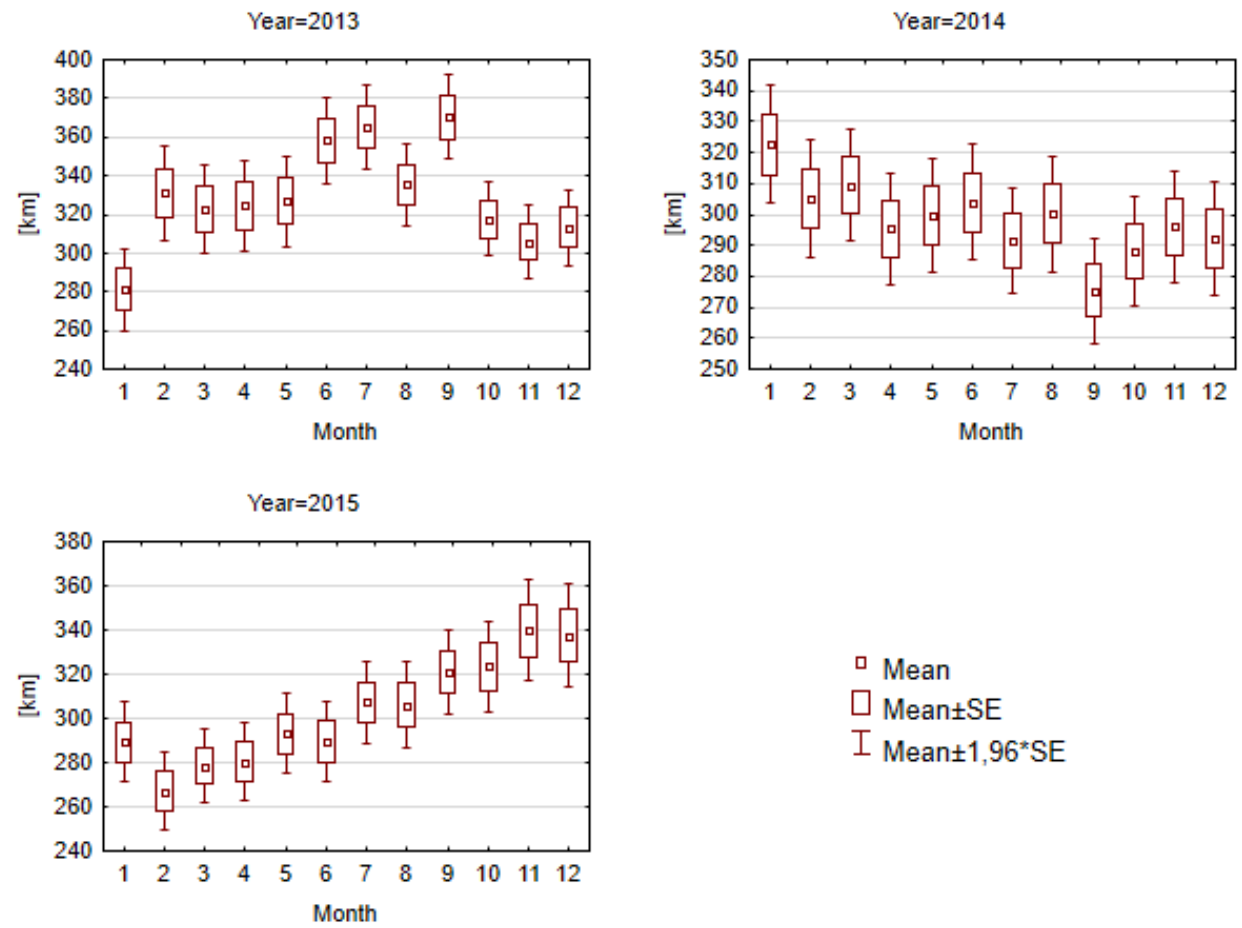

Fig. 6. Categorized box plot for month as an independent variable, and daily kilometrage as a dependent variable - daily kilometrages of Category IV vehicles

2013 their daily kilometrages varied considerably throughout the year. The greatest differences were recorded for January, June, July and September. In 2014, the differences were negligible and observed only between January and September, while in 2015 the differences were recorded in February, September and November.

Figure 6 shows a box-and-whisker diagram (box plot) which is a graphic representation of daily kilometrages for Category IV vehicles in each month throughout the year.

\section{CONCLUSIONS}

The results of the statistical analysis of daily kilometrages of four categories of vehicles used over three consecutive years in the selected transport company show that:

- in 2013, statistically significant differences in daily kilometrages were observed for each of the four vehicle categories;
- in 2014 there were no significant differences between daily kilometrages of Category I and III vehicles;

- in 2015 there were no significant differences between daily kilometrages of Category I and II vehicles.

For the other vehicle categories the differences were statistically significant, so it seems reasonable to conduct further analyses of data on vehicle use separately for each vehicle category.

In addition, statistical analyses of daily vehicle kilometrages for the four categories of vehicles showed statistically significant differences throughout the year. However, these differences did not show full repeatability in the subsequent years of vehicle use. This could be due to both internal changes in the company's vehicle management policy and changes on the domestic transport market observed during those three years. The partial repeatability of statistically significant

Table 9. Results of the Kruskal-Wallis test for daily kilometrages of Category IV vehicles

\begin{tabular}{|c|c|c|c|}
\hline Year & K-W Statistic's value & $\mathbf{p}$ - value & Are there differences decision \\
\hline 2013 & 149,7663 & 0,0000 & Yes \\
\hline 2014 & 20,7667 & 0,0359 & Yes \\
\hline 2015 & 61,1535 & 0,0000 & Yes \\
\hline
\end{tabular}


differences in daily kilometrages across vehicle categories was found in the following months throughout the consecutive years:

- Category I vehicles showed repeatable differences in daily kilometrages in July and November;

- Category II vehicles did not show any repeatable differences in daily kilometrages;

- Category III vehicles showed repeatable differences in daily kilometrages in May;

- Category IV vehicles showed repeatable differences in daily kilometrages in September.

\section{REFERENCES}

1. Abramov, I., Turygin, Y., Sosnovich, E., Bako, B.: Control System Simulation of Technical Equipment. In. Procedia Engineering, Vol. 149, 2016, pp. 566-570.

2. Bobrowski, D.: Probability in technical applications. WNT, Warsaw 1986.

3. Dobosz M.: Wspomagana komputerowo statystyczna analiza wyników badań. Wydawnictwo EXIT. Warszawa, 2004.

4. Droździel, P., Komsta, H., Krzywonos, L.: An analysis of cost of vehicles repairs in a transportation company. Part I. In. Transport Problems, Vol. 7, Issue 3, 2012, pp. 67-75.

5. Droździel, P., Komsta, H., Krzywonos, L.: An analysis of unit repair costs as a function of mileageof vehicles in a selected transport company. In. Transport Problems, Vol. 9. Issue 4, 2014, pp. 87-95.

6. Greene, D., Liu, J., Khattak, A., Wali, B., Hopson, J., Goeltz, R.: How does on-road fuel economy vary with vehicle cumulative mileage and daily use? In. Transportation Research Part D: Transport and Environment, Vol. 55, 2017, pp. 142-161.

7. Koźlak A.: Ekonomika transportu. Teoria i praktyka gospodarcza. Wydawnictwo Uniwersytetu Gdańskiego. Gdańsk 2007.

8. Krzywonos, L., Nieoczym, A., Siłuch, D., Krzysiak, Z.: Analysis of vehicle repair costs to the transport company. In. Logistics 6/2014, pp. 6220-6224.

9. Ma, H., Xie, H., Huang, D., Xiong, S.: Effects of driving style on the fuel consumption of city buses under different road conditions and vehicle masses. In. Transportation Research Part D: Transport and Environment, Vol. 41, 2015, pp. 205-216.

10. Mendyk, E.: Transport economics. Publisher School of Logistics in Poznań. Poznań 2009.

11. Michalski, R., Wierzbicki, S.: An analysis of degradation of vehicles in operation. In. Maintenance and Reliability, Vol. 40, 1/2008, pp. 30-32.

12. Wei, Z., Nikbin, K.: Statistical Characterization, Pattern Identification, and Analysis of Big Data. In. SAE Int. J. Mater. Manf., Vol. 10, Issue 3, 2017, pp. 293-305.

13. Yun, U., Ryang, H., Kwon, O.: Monitoring vehicle outliers based on clustering technique. In. Aplied Soft Computing, Vol. 49, December 2016, pp. 845-860. 